\title{
Psychoactive drug use by medical students: a review of the national and international literature
}

\author{
Escola Paulista de Medicina, \\ Faculdade de Ciências Médicas da Santa Casa de São Paulo, Faculdade de Ciências Médicas da Universidade \\ Estadual de Campinas, Faculdade de Medicina do ABC, Faculdade de Medicina de Marília, Faculdade de Medicina de \\ Santo Amaro, Faculdade de Medicina da Universidade Estadual Paulista - Campus Botucatu, Faculdade de Medicina \\ da Universidade de São Paulo, Faculdade Regional de Medicina de São José do Rio Preto.
}

Non-medical drug use among medical students is a major concern among researchers and policy makers in several countries, not only because of the personal harmful consequences that may arise from this behavior, but also for the social consequences. This article aims to evaluate national and international data available on non-medical drug-use among medical students and risk factors associated with these problems, as well as social and institutional implications. Prevalence rates, in Brazilian and international samples, of alcohol and drug use, abuse and dependence, reasons for onset, methodological issues, and the role of medical education are presented, compared and discussed. The authors suggest some issues that should be a addressed in order to deal with this complex situation.

UNITERMS: Drugs, medical students, dependency, prevention and medical education.

\section{INTRODUCTION}

I $\mathrm{n}$ recent years, the problem of non-medical use of psychoactive drugs by medical students and physicians has become an area of growing interest and concern for researchers, educational institutions and medical associations. ${ }^{1-8}$ Physicians themselves can be seen as occupying diametrically opposite, and at times conflicting positions in relation to substance misuse; on the one hand they have a higher prevalence of drug misuse, but on the other they also have a pivotal role to play in the early detection of drug misuse, including among colleagues, and referral to appropriate services. ${ }^{9-12}$

Address for correspondence:

Ana Maria Mesquita

Rua Haddock Lobo, 1272 apto. 71 - Cerqueira César

São Paulo/SP - Brasil - CEP 01414-002
The aims of this review are three-fold. First, to evaluate the published data on the non-medical use of drugs among Brazilian medical students. Secondly, to compare these findings with studies from other countries, and finally to look at how interventions aimed at identifying and treating this problem might be developed.

\section{BRAZILIAN STUDIES}

To date there have been four published studies looking at the prevalence of drug misuse among Brazilian medical students. ${ }^{8.13-15}$ The work of Silva et al, $1985^{x}$ has various methodological problems which limit the interpretation of the results and make it difficult to compare them with those of other studies. In particular, the questionnaire that Silva et al. used to collect information on drug misuse does not seem to have been validated, there 
is no mention as to how the sample of students was obtained, and the criteria used to define drug misuse are extremely unclear. Consequently, this study will not be considered further. The studies by Mesquita et al. and Andrade et al. ${ }^{13.15}$ were based on the same population, namely the School of Medicine of the University of São Paulo, while that of Andrade, $1995^{14}$ was undertaken in a group formed by nine medical schools in the state of São Paulo' called the Consortium.

There are no similar studies of the general population that could be used for comparison, therefore, we reviewed several studies of drug use among university students in general. ${ }^{16-23}$ Unfortunately, these also suffer from serious methodological problems, as was pointed out by Almeida Filho $^{24}$ in a review of drug misuse in Brazil in 1991. These problems include: unrepresentative samples, nonstandardized definitions of drug misuse, use of nonvalidated questionnaires of unknown reliability, unclear data collection methods and inadequate data analysis. Consequently, only the more methodologically rigorous study by Magalhães et al., $1991^{20}$ will be used for comparison. The studies by Magalhães et al., 1991, Mesquita et al., 1995 and Andrade et al., 1995 will be examined in more detail in the following section.

Magalhães et al., 1991. This study was undertaken using a representative sample $(n=1,069)$ of university students from various faculties in the city of São Paulo, using an instrument based on that recommended for student surveys by the World Health Organization (WHO). ${ }^{25}$ The authors examined the prevalence of the non-medical use of 11 psychoactive substances over two time periods: lifetime use and use in the previous three months. The prevalence of use of the various substances is shown in Table 1.

Among the illicit drugs, cannabis was the most commonly used, with 26 percent reporting lifetime use, of whom 4 percent described themselves as heavy users (smoking once or more per day). Factors that were associated with more frequent drug use were: holidays, traveling, friends, ease of obtaining the drug and personal crises. Factors which seemed to protect against drug use were: living with family, having a girlfriend or boyfriend, health problems and work problems.

Mesquita et al., 1995 - This study was undertaken in 1991 amongst all students at the School $\mathrm{p}<0.01$ ). of Medicine of the University of São Paulo (FMUSP) and had a response rate of 74 percent $(n=796)$. A modified version of the questionnaire proposed by $\mathrm{WHO}^{25}$ was also employed and further qualitative information was obtained using focus groups. Questions covered the non-medical use of 11 substances, with use being classified into: lifetime use, use in the past 12 months and use during the past 30 days. Information was also collected on age at first use, reasons for using, attitudes towards drugs and attitudes towards drug-dependent patients.

The prevalence figures are shown in Tables 1 and 2 . Apart from alcohol and tobacco, the most commonly used substances were cannabis and tranquilizers, both of which were more commonly used by students in the final years of medical school.

Qualitative data from the focus groups suggested that competitiveness, heavy work loads, contact with patients, and the proximity of the residency examination were seen as contributory factors for drug use. At the same time, students reported that their scientific knowledge of the effects of these substances protected them from developing drug-related problems.

A logistic regression analysis revealed that three factors were associated with a greater probability of drug use, excluding cannabis and the use of inhalants and tranquilizers in the past 12 months: being towards the end of the medical course, approving of drug experimentation by others, and frequenting bars as a leisure activity. One factor was associated with a reduced risk of drug taking; not having someone to confide in about personal problems.

Andrade, 1995 - This study, undertaken in 1994, encompassed all students at nine medical schools in the

Table 1

Lifetime prevalence of psychoactive substance use among Brazilian medical and university students

\begin{tabular}{l|c|c|c}
\hline & Mesquita et al. & Magalhães et al. & Andrade \\
& 1991 & 1991 & 1995 \\
& $(n=796)$ & $(n=1,069)$ & $(n=3,725)$ \\
& $\%$ & $\%$ & $\%$ \\
\hline Alcohol* $^{*}$ & 82 & 82 & 89 \\
Tobacco & 39 & 39 & 39 \\
Solvents & 23 & 28 & 31 \\
Cannabis & 19 & 26 & 24 \\
Tranquilizers & 11 & $\star \star$ & 11 \\
Amphetamines & 5 & $\star \star$ & 8 \\
Cocaine $^{\star}$ & 4 & 10 & 5 \\
\hline
\end{tabular}

* Differences between Magalhães et al.'s and Andrade's studies ( $X^{2}$ test, 
Table 2

Use of psychoactive substances by Brazilian medical students in Andrade's (A) and Mesquita et al.'s (B) samples, by academic year.

\begin{tabular}{|c|c|c|c|c|c|c|c|c|c|c|c|c|c|}
\hline \multirow[t]{4}{*}{ Substance } & \multirow[t]{4}{*}{ Type of use } & \multicolumn{12}{|c|}{ Year } \\
\hline & & \multicolumn{2}{|c|}{ 1st } & \multicolumn{2}{|c|}{ 2nd } & \multicolumn{2}{|c|}{ 3rd } & \multicolumn{2}{|c|}{ 4th } & \multicolumn{2}{|c|}{5 th } & \multicolumn{2}{|c|}{ 6th } \\
\hline & & A & B & A & B & A & B & A & B & A & B & & B \\
\hline & & \multicolumn{2}{|c|}{$\%$} & \multicolumn{2}{|c|}{$\%$} & \multicolumn{2}{|c|}{$\%$} & \multicolumn{2}{|c|}{$\%$} & \multicolumn{2}{|c|}{$\%$} & \multicolumn{2}{|c|}{$\%$} \\
\hline \multirow[t]{3}{*}{ Alcohol } & Lifetime & 84 & 84 & 90 & 80 & 87 & 92 & 89 & 91 & 92 & 91 & 92 & 89 \\
\hline & Past 12 months & 78 & 78 & 84 & 77 & 79 & 87 & 83 & 86 & 87 & 83 & 87 & 87 \\
\hline & Past 30 days & 43 & 73 & 48 & 68 & 45 & 80 & 48 & 77 & 51 & 73 & 53 & 74 \\
\hline \multirow[t]{3}{*}{ Tobacco } & Lifetime & 34 & 32 & 39 & 29 & 41 & 46 & 35 & 34 & 45 & 52 & 43 & 48 \\
\hline & Past 12 months & 21 & 17 & 22 & 14 & 25 & 23 & 20 & 17 & 29 & 17 & 22 & 17 \\
\hline & Past 30 days & 9 & 16 & 9 & 7 & 9 & 12 & 8 & 14 & 12 & 4 & 7 & 11 \\
\hline \multirow[t]{3}{*}{ Cannabis } & Lifetime & 18 & 7 & 23 & 12 & 26 & 24 & 23 & 30 & 30 & 20 & 29 & 24 \\
\hline & Past 12 months & 11 & 5 & 17 & 10 & 20 & 15 & 15 & 19 & 20 & 4 & 14 & 14 \\
\hline & Past 30 days & 6 & 3 & 9 & 7 & 9 & 12 & 8 & 14 & 12 & 4 & 7 & 11 \\
\hline \multirow[t]{3}{*}{ Solvents } & Lifetime & 26 & 20 & 33 & 20 & 32 & 28 & 29 & 24 & 35 & 19 & 34 & 28 \\
\hline & Past 12 months & 19 & 9 & 23 & 15 & 20 & 18 & 16 & 9 & 22 & 5 & 17 & 13 \\
\hline & Past 30 days & 10 & 7 & 12 & 11 & 10 & 7 & 6 & 9 & 12 & 5 & 9 & 8 \\
\hline \multirow[t]{3}{*}{ Tranquilizers } & Lifetime & 7 & 4 & 7 & 4 & 11 & 8 & 13 & 9 & 12 & 17 & 17 & 24 \\
\hline & Past 12 months & 4 & 1 & 5 & 2 & 7 & 8 & 9 & 7 & 6 & 13 & 1 & 13 \\
\hline & Past 30 days & 2 & 1 & 2 & 2 & 4 & 7 & 4 & 6 & 3 & 11 & 8 & 11 \\
\hline \multirow{3}{*}{ Amphetamines } & Lifetime & 3 & 1 & 6 & 1 & 10 & 5 & 9 & 7 & 8 & 7 & 12 & 9 \\
\hline & Past 12 months & 2 & 0 & 5 & 1 & 7 & 5 & 5 & 4 & 6 & 3 & 7 & 4 \\
\hline & Past 30 days & 1 & 0 & 1 & 0 & 4 & 4 & 1 & 3 & 3 & 2 & 2 & 4 \\
\hline \multirow[t]{3}{*}{ Cocaine } & Lifetime & 2 & 1 & 4 & 0 & 6 & 5 & 4 & 7 & 6 & 4 & 6 & 7 \\
\hline & Past 12 months & 0 & 0 & 2 & 0 & 3 & 3 & 3 & 5 & 4 & 1 & 3 & 5 \\
\hline & Past 30 days & 0 & 0 & 1 & 0 & 2 & 3 & 1 & 4 & 2 & 2 & 2 & 3 \\
\hline
\end{tabular}

State of São Paulo and had a response rate of 71 percent $(n=3,725)$. The author used a modified version of the instrument that had been used by Mesquita et al. (1995). Questions were asked about the use of the same 11 substances over the same three time periods described in the previous study. The full statistical analysis of these results has yet to be published and the prevalence figures presented here in Tables 1, 2 and 4 are derived from the final report that was sent to the study's research funding body.

\section{COMPARISONS BETWEEN THE THREE STUDIES}

One of the problems in comparing the studies of Mesquita et al. and Andrade is that some of the students interviewed in the former were also interviewed in the latter. However, as there was a three-year time gap between the studies, we calculate that this overlap represents no more than 10 percent of Andrade's total sample.

As the questionnaires in all three studies were completed anonymously, there was no way of approaching those students who were not present on the day of the survey. Since various authors have suggested that in studies of student populations, those students who are absent on the day of the survey are more likely to be drug users, ${ }^{1.5}$ the true prevalence of drug misuse may have been underestimated.

Comparing the two studies of medical students (see Table 2), the following similarities can be seen: the prevalence of drug use tends to increase from the first to sixth year for most substances and over most time intervals; the sequence of lifetime drug use from highest to lowest prevalence figures follows the same order: alcohol, 
tobacco, solvents, cannabis, tranquilizers, amphetamines to cocaine; and there tends to be a prominent increase in the prevalence of tranquilizer use in the fifth and sixth years. The remarkable increase in the recent use of tranquilizers can be verified in both studies.

In Table 1, statistical comparisons using the chisquared test between university students in general and medical students show that medical students have a higher lifetime prevalence of alcohol use ( 89 vs. 82 percent, $\mathrm{p}<0.01)$ and a lower lifetime prevalence of cocaine use ( 5 vs. 10 percent, $\mathrm{p}<0.01$ ). University students show the same declining order of prevalence of substance misuse from alcohol to cocaine, as seen in the other two studies.

Although several authors have observed that use of prescription drugs is more common among medical students, ${ }^{1.5 .12}$ we were unable to investigate this, as Magalhães et al. did not ask a separate question about tranquilizer use, but combined it with amphetamine use. Both Mesquita et al. and Andrade demonstrated the relatively high prevalence of tranquilizer use among medical students (11 and 8 percent in the past 30 days, respectively).

\section{GENERAL CONSIDERATIONS ABOUT BRAZILIAN STUDIES}

The early studies of drug use in Brazil tended to be fairly simple prevalence studies, often with unclear objectives and little thought given to methodological design. These studies rarely did more than attempt to correlate drug use with such variables as social class, and used statistical analyses no more complicated than the chisquared test.

Magalhães et al.'s 1991 study marks a turning point in this respect. They were concerned about such factors as sampling methods that allow data to be collected on representative samples of the target population, thus permitting a greater degree of generalization, the use of validated questionnaires, and the formulation of more precise objectives. More recent studies, such as Mesquita et al., have adopted a mixture of quantitative and qualitative methods to more fully investigate the problem.

The studies of Mesquita et al. and Andrade have enabled further advances, including the following: (1) the use of more specific hypotheses; (2) more rigorous and diverse statistical methods, e.g. logistic regression analysis, which permit more complex analyses than simple bivariate correlations; and (3) standardized methodologies which allow for the reproduction and comparison of results with those of other studies.

It is important to point out that medical students differ from university students mainly in relation to alcohol and lifetime cocaine use. Finally, lifetime use of both cocaine and amphetamines, as use of tranquilizers during the last 30 days, presented considerably higher rates among medical students.

\section{INTERNATIONAL STUDIES OF DRUG USE AMONG MEDICAL STUDENTS}

Using the data banks Medline and Lilacs, 22 articles published between 1970 and 1995 on drug use among nonBrazilian medical students were found. Most of the more recent studies were conducted in the United States, ${ }^{12.45 .12 .26}$ with the exception of one study undertaken in Cuba, ${ }^{6}$ and another that used a sample obtained from 42 different countries. $^{27}$

Samples: In the studies by Baldwin

Table 3

Highest and lowest prevalence figures for psychoactive substance use among medical students found in the international literature

Prevalence

\begin{tabular}{lcccc} 
Substance & \multicolumn{2}{c}{ Lifetime use } & \multicolumn{2}{c}{ Recent use } \\
& Lowest & Highest & Lowest & Highest \\
\hline Alcohol & 96 & 98.1 & 64 & 88 \\
Tobacco & 32 & 55 & 7 & 13.7 \\
Cannabis & 53 & 68 & 9 & 3.6 \\
Tranquilizers & 20 & 37 & 3 & 12.8 \\
Amphetamines & 20 & 23 & 0.3 & 3 \\
Cocaine & 19 & 37 & 0 & 20 \\
\hline
\end{tabular}
et al. ${ }^{1}$ and McAuliffe et al., ${ }^{5}$ stratified random samples were used based on criteria such as: geographic region, medical school size, type of school (private or public) and the proportion of female students. In other studies, sample selection was simply based on specific medical schools and specific years. In the study by Crofton et al., ${ }^{27}$ no information is provided as to how the sample was selected.

Data collection: In all the studies, with the exception of that of Crofton et al., ${ }^{27}$ 
Table 4

Comparison of the prevalence of psychoactive substance use among finalyear medical students from one Brazilian and one North American study.

\begin{tabular}{|c|c|c|c|}
\hline Substance & Type of Use & $\begin{array}{c}\text { Andrade } \\
1995 \\
(n=3,725) \\
\%\end{array}$ & $\begin{array}{c}\text { Baldwin et al. } \\
\begin{array}{c}1991 \\
(n=2,046) \\
\%\end{array}\end{array}$ \\
\hline
\end{tabular}

Alcohol

$\begin{array}{lll}\text { Lifetime }^{*} & 92 & 98 \\ \text { Past } 12 \text { months }^{*} & 87 & 94 \\ \text { Past } 30 \text { days }^{*} & 53 & 87\end{array}$

Tobacco

$\begin{array}{lrr}\text { Lifetime }^{\star} & 43 & 55 \\ \text { Past } 12 \text { months }^{\star} & 22 & 13 \\ \text { Past } 30 \text { days } & 8 & 10\end{array}$

Cannabis

$\begin{array}{lrl}\text { Lifetime }^{*} & 29 & 66 \\ \text { Past } 12 \text { months }^{*} & 14 & 22 \\ \text { Past } 30 \text { days } & 7 & 10\end{array}$

Tranquilizers

$\begin{array}{lrr}\text { Lifetime } & 17 & 19 \\ \text { Past } 12 \text { months } & 12 & 7 \\ \text { Past } 30 \text { days }^{*} & 8 & 2\end{array}$

Amphetamines

$\begin{array}{lrr}\text { Lifetime }^{*} & 12 & 22 \\ \text { Past } 12 \text { months }^{\star} & 7 & 1 \\ \text { Past } 30 \text { days }^{* *} & 2 & 0\end{array}$

Cocaine

\begin{tabular}{lrr} 
Lifetime $^{*}$ & 6 & 32 \\
Past 12 months & 3 & 10 \\
Past 30 days & 2 & 2 \\
\hline
\end{tabular}

${ }^{*} X^{2}, \mathrm{p}<0.01$

** Fisher's Exact Test, one-tailed, $\mathrm{p}=0.00142$

self-completed, anonymous questionnaires were used which were mailed to students. In some cases, the students were paid to participate in the study. Students who did not return the questionnaire were then mailed an additional two copies before being considered non-responders. The response rates varied from 37 to 100 percent. The questionnaires had generally been adapted from those used in previous student surveys, thus facilitating comparison between studies.

In Crofton et al.'s multi-center and multi-country study, the method of data collection used was left to the discretion of the local study coordinators. Further details are not given beyond the information that the questionnaires were completed in the students' class rooms.
Variables studied: The majority of studies, with the exception of Crofton et al. ${ }^{27}$ and Menendez and Calabuch," asked questions about the use of licit drugs, illicit drugs and nonprescription medications. Lifetime use and use during the previous year and previous 30 days were the most commonly used time intervals. Some studies also asked about lifetime abuse and dependence. This was assessed either by means of self-report or by use of the CAGE questionnaire for alcohol dependence.

Sociodemographic date were collected in all surveys. Other studied aspects included: access to drugs, reasons for use, attitudes towards drug use by physicians, knowledge of prevention and treatment programs, personality factors associated with abuse/ dependency, knowledge of drug-related dangers, and the type of drug abuse training offered by the medical school.

Principal findings: As can be seen in Table 3, with the exception of amphetamines, there is a remarkable degree of variation in the use of all reported substances, be it for lifetime or recent use. Because of the differences in the way the studies were undertaken, it is difficult to interpret how much of this variation is real, and how much is a methodological implication. Maddux et al. ${ }^{12}$ found a prevalence of substance abuse of 11 percent, which in conjunction with illicit substance use was associated with a depressive affect. McAuliffe et al. ${ }^{5}$ found that 16.5 percent of students had met criteria for drug abuse at some time during their lives. The same authors also found that 5.2 percent of students reported having experienced drug dependency, which compares to the 2.8 percent of students who were found to be CAGE positive in Menendez and Calabuch's study. ${ }^{6}$

Comparing two North American groups, Baldwin et al.' confirmed that medical students had a higher 
probability of using alcohol, tranquilizers and psychedelic drugs (excluding LSD).

According to McAuliffe et al.'s study, ${ }^{5}$ "experimentation" was the most commonly reported reason for using drugs, and recreational use was found to be twice as common as self-medication. Kory and Crandall, $1986,{ }^{4}$ found that recreational use of an individual drug was a positive predictor of the use of other substances.

Maddux et al., 1986, ${ }^{12}$ showed that first-time use of cocaine and benzodiazepines occurred more commonly during medical school than in high school. The authors suggested that first-time benzodiazepine use during medical school was probably due to ease of access to these drugs, while first-time cocaine use was more dependent on age, a tendency also observed in non-medical students.

McAuliffe et al. ${ }^{5}$ discovered that the prevalence of drug use was even higher in the clinical years of medical school, while Kory and Crandall ${ }^{4}$ found that drug use was associated with age, gender, and a greater number of absences.

\section{COMPARISON OF THE BRAZILIAN AND NORTH AMERICAN STUDIES}

To facilitate comparison between the Brazilian and North American studies, Baldwin et al.'s study will be focused on because although it only provides data on final year students, it has a large representative sample and uses the same criteria for drug use.

Baldwin et al., 1991 - this study was undertaken in 1987 and used a large national sample of medical students $(n=2,046)$ from 23 North American medical schools. Selection criteria included the geographical region in which the school was located, size, and whether the institution was private or public. The sampling procedure also took into account the student sex ratio. Data were collected using anonymous, self-completed questionnaires returned by mail.

Table 4 compares the results of Baldwin et al.'s study with the data on final year students from Andrade's study. In terms of lifetime use, North American students showed a significantly higher prevalence for the use of alcohol, tobacco, cannabis, amphetamines and cocaine $(\mathrm{p}<0.001)$. Brazilian students showed a higher 12-month prevalence for tobacco, tranquilizer and amphetamine use, and a higher 30-day prevalence for tranquilizers and amphetamines use.
Although the differences in the lifetime prevalence of drug use between the two populations (in particular cannabis and cocaine) are greater than past 30 days use, the Brazilian sample had a greater tendency towards recent non-medical use of tranquilizers and amphetamines. These results may suggest a greater tendency towards drug experimentation among North American students, and possibly more dependency problems among the Brazilian sample, in regards to these medications.

\section{METHODOLOGICAL CONSIDERATIONS OF THE INTERNATIONAL STUDIES}

A factor common to virtually all the studies is the use of anonymous, self-completed questionnaires which were mailed back to the research groups. Although this method allows reaching a larger population and is without a doubt cheaper, the reliability of some of the responses may be questionable. Further, the response rate is often lower than the "in loco" data collection procedure, and these studies rarely compare the nonrespondent and respondent groups as to sociodemographic variables.

It is also important to question the precision of the data collected, as the authors of the studies never presented a definition of the abuse and dependency criteria to the respondents. Other studies have shown that medical students have a general lack of knowledge in relation to drugs and drug misuse, ${ }^{28-32}$ including difficulty in making substance abuse-related diagnoses. ${ }^{31-34}$ Therefore, selfreports of abuse and dependency probably lack validity and reliability, and should only be made using validated diagnostic scales.

Precise questioning of the reasons for drug use is often lacking. Most studies can be criticized for not differentiating experimental, recreational, self-treatment and use of drugs for the purpose of improving performance, which would permit a more precise conclusion as to the groups, situations and substances urgently requiring attention.

Several of the studies show that initiation into drug use occurs during medical school, but because comparison data from age-and-social-class-matched non-medical students is rarely presented, it is difficult to know how much experiences particular to medical school are responsible for this. 


\section{DISCUSSION}

The current picture of psychoactive substance use among medical students, in spite of all national and international studies, is still far from clear. The results from both Brazilian and international studies are remarkably consistent, although there are some notable differences in the prevalence of cannabis and cocaine use by North American and Brazilian students.

By and large, alcohol is the drug with the highest lifetime prevalence and stimulants the lowest. Of particular concern among the Brazilian studies is the relatively high prevalence of recent tranquilizer and amphetamine use, which increases with time spent at medical school. Indeed, there is a general trend for the reporting of drug use to increase for all categories as students pass from the first to the final year. It is important to point out that the Brazilian studies were not carried out with national samples, and therefore the results may reflect regional trends.

The higher prevalence rates of non-medical use of amphetamines and tranquilizers in the Brazilian sample may be associated with various factors: 1) although controlling access to these substances has received more attention in the past few years, it is still not difficult to obtain them without going through proper procedures; 2 ) the issue of drug misuse among medical students has been addressed by U.S. society for more than 20 years now, ${ }^{3.35}$ through conferences, implementation of drug-use policies at medical schools, and prevention programs. Therefore, the lower prevalence rates presented by the North American samples may reflect the results of these actions; and this difference may also be verified in the general population, reflecting a major governmental and social attitude towards drug use.

Regarding the comparison of the prevalence presented by the Brazilians samples of university and medical students, there seems to be little difference except for lifetime use of alcohol and cocaine. The lower prevalence rate of cocaine use verified in the medical students' sample may be related to their exposure during their training to the harmful effects of this substance. However, their increased knowledge of the effects and properties of medications seems to give them a false sense of control over their own use of these substances. ${ }^{15}$ This, allied to facilitated access to the medications, enhances the probability of medical students electing them as their drugs of choice.

The higher prevalence rates observed in the last year of medical school (the sixth year in Brazil), when compared to the initial years, deserve consideration. Different levels of drug involvement due to various personal reasons ${ }^{36}$ are expected across all groups of society, and therefore, this effect should also be reflected in the majority of medical students and faculty members, as well as practitioners. ${ }^{10}$

As has already been remarked, there is a conspicuous lack of information about the reasons for drug use, the context in which it occurs, the personality traits of those involved and how these relate to other risk factors. Furthermore, once drug use has been initiated, little is known about what maintains this behavior. These questions point to areas where further research is needed, and also to the need to combine quantitative methodologies with qualitative ones to obtain a more complete picture of drug use.

In the study by Mesquita et al., 1991, ${ }^{15}$ students believed that stress was an important factor in drug use, in particular stress associated with competitiveness, the great number of hours worked, certain aspects of clinical work, and the pending residency exam. However, even here students may be over simplifying and rationalizing the situation. For example, are the reasons for using cannabis the same as those for using cocaine or misusing alcohol? As yet we are unable to answer these questions.

However, a more thorough evaluation of the reasons for the use of these drugs by medical students would surely indicate factors that increase the probability of drug-related problems associated with the medical profession and environment. That medical students experience considerable stress is without question, as has been shown by other studies.$^{37.38}$ McCue, $1982,{ }^{38}$ described a variety of stresses that students experience, for example: intimate and frequent contact with pain and suffering, physical and emotional contact with patients, death, and the uncertainty of much of medical science in contrast to the desires that patients have for certainty and guarantees.

In one study of Brazilian medical students, Martins, $1994,{ }^{37}$ found three main areas in which residents expressed difficulties: breaking bad news, treating patients with terminal disease, and the fear of contracting infectious diseases. The residents also pointed to two particular stresses: fear of making a mistake and lack of time to spend with family and friends.

Drug use by medical students can cause a variety of problems, depending on the degree of involvement that the student has with the drug. The effects of occasional use largely depend on the circumstances in which he uses the drug, but may range from no discernible effect to a serious impairment in academic performance and concentration difficulties. There is also an increased risk of abuse or even dependency later in life, with the associated personal and social complications that ensue. Early detection of drug problems for this population, 
ideally while the student is still in medical school, should be a priority of any drug prevention/intervention program.

To better facilitate such early detection, there is an urgent need for research investigating the risk factors associated with initiation into drug use. Such studies need to go beyond the confines of merely examining factors related to the pressures of medical training, and look at factors that predate entry into medical school, such as family problems, personality traits and prior experimentation with other drugs.

Most medical schools in Brazil lack a structural framework which would allow students with drug problems to be identified. One possibility would be to have a type of tutorial system, in which a designated professional, with a pastoral/counselling function, would meet with a small group of students on a regular basis from the start of the course until the end. This type of approach would permit the development of a more trusting and confidential relationship than is normally possible with academic staff. Such a professional would be ideally placed to identify students with drug or other psychological problems, and to offer treatment where appropriate. Treatment would have to be completely confidential and held away from school premises to ensure that students would not be identified as "drug addicts" by their classmates.

When the person who identifies drug misuse in a student is a physician, his or her own attitudes toward, and personal experience with, drug use come into play. Physicians with more liberal attitudes to drug use and those who have experimented with drugs in the past may be more disposed to play down the importance of drug misuse by colleagues or students, and consequently be less likely to intervene at an early stage and offer treatment.

Extensive literature exists showing that medical students have negative attitudes towards patients with drugdependency problems. ${ }^{32.39 .40-44}$ It is likely that these attitudes are formed or at least reinforced during medical school. If medical schools are to have a pivotal role in preventing drug and alcohol problems among students, then these attitudes need to be more effectively challenged. However, at the present time the amount of drug and alcohol training that most medical students receive is minimal ${ }^{7.32 .41 .44-46}$ and fragmented. ${ }^{3.7 .32 .39,41.47}$ Nocks $^{44}$ states that negative attitudes towards drug-dependent patients increase during the medical course because students feel inadequately prepared to manage these situations.

Regarding drug-related problems, they may lack the necessary skills to identify drug problems and deal with denial. ${ }^{3.32 .39}$ According to Negrete, ${ }^{35}$ such difficulties are aggravated by the unhelpful attitudes that many clinicians have towards this group of patients, including a distaste for illnesses characterized by frequent relapses, moralistic attitudes towards patients who drink too much, beliefs that drug and alcohol misuse are social rather than medical problems, and the difficulty many physicians have in comprehending why patients misuse drugs at all.

Consequently, when faced with a drug or alcohol abusing colleagues or classmates, the student may be paralyzed into inaction due to a combination of fear of confronting the person and inappropriate therapeutic nihilism. Often the little contact that students have with drug and alcohol dependent patients is fairly short-term and is likely to be with those patients who have more chronic problems associated with psychiatric and physical complications. ${ }^{3.32,41.44 .48}$ They are unlikely to see patients who have achieved stable abstinence and social reintegration, first because these patients often drop out of treatment, and secondly because such an outcome may take several years to achieve. Consequently, students may not believe that these patients can be successfully rehabilitated, and therefore become unduly pessimistic in their outlook.

While physicians allegedly make bad patients, they may also make bad physicians when the patient they are treating is another doctor. There may be an unwillingness for colleagues to take control of the situation, allowing the doctor-patient to take liberties that would not be allowed with ordinary patients. Thus corridor consultations, inadequate supervision and permitting selfprescribing are common, behaviors that are rationalized on the grounds that busy schedules and on-call commitments make it difficult to find time to make proper consultations.

These lessons are learned early on at medical school, particularly in relation to the use of benzodiazepine to relieve symptoms of stress or induce sleep after a period of on-call duty. While such behavior may not lead to drug dependency, it is undesirable. ${ }^{23}$ Indeed, consideration should be given to prohibiting self-prescribing among physicians, and only allowing physicians to prescribe to colleagues who have registered with them as patients. Specialized services for students and practicing physicians need to be developed to counteract this tendency and to provide medical professionals with the treatment service they deserve.

In Brazil, it is common practice for final-year medical students to have facilitated access to prescription drugs. Drugs are often donated by pharmaceutical companies for use with impoverished patients who cannot afford to pay for them, and in some institutions, medical students themselves staff these small pharmacies. Such easy access only encourages students to self-prescribe. Later, this may lead to the inappropriate or improper prescribing of 
psychotropic drugs by one doctor to a colleague, patient, or even to himself. In Brazil, consideration should be given to ending the relatively unlimited and unsupervised access that many students and physicians have to pharmacies.

To really tackle the problem of drug and alcohol misuse by medical students and physicians, particularly in terms of prevention, early identification and treatment, we must do much more than simply tinker with the medical school curriculum. The following six recommendations offer a framework of where to go from here:

1. Review the curriculum, not only regarding the amount of time spent dealing with this subject during the course, but also as to the themes and techniques employed, in order to increase the knowledge base that medical students have about drug and alcohol misuse. In particular, information about misuse by medical professionals and how to identify and deal with such problems must be covered and emphasized, especially reinforcing the dangers involved in self-prescription.

2. Provide for better and more appropriate clinical experience with patients with drug and alcohol problems, based on directly supervised case management.

3. Require medical school authorities to develop a system in which students who are having problems during the medical school course can be identified and counselled, such as the modified tutorial system mentioned above. A similar system needs to be developed for residents and other physicians.

4. Organizations representing the medical profession, such as regional medical counsels, need to develop a system whereby students and physicians identified as having drug and alcohol problems can be assessed and treated confidentially. In resistant cases, there may need to be an element of compulsion.

5. Formulate and implement a formal policy regarding drug-related issues in the school of medicine, applicable to all members of the academic community: board of directors, staff, faculty and students.

6. Undertake further research to investigate risk factors for drug and alcohol misuse, and whether these can be minimized.

\section{Resumo}

Problemas relacionados ao uso nāo-médico de substâncias psicoativas por estudantes de medicina tem apresentado um interesse crescente por parte de vários setores da comunidade, não apenas pelas possiveis consequências pessoais deste uso, mas tambem pelas consequências sociais. O presente artigo tem como objetivo avaliar dados nacionais e internacionais de uso não-médico de substâncias psicoativas por estudantes de medicina, bem como fatores de risco para problemas relacionados a este uso e implicaçōes sociais e institucionais. Tópicos como prevalências de uso, abuso e dependência, questōes metodológicas, razōes para uso, bem como o papel das escolas médicas são discutidos. Os autores apresentam sugestōes para abordagem científica e técnica de problemas relacionados ao uso de drogas por esta população.

\section{REFERENCES}

1. Baldwin Jr DC, Hughes PH, Conard SE, Storr CL, Sheehan DV. Substance use among senior medical students: a survey of 23 medical schools. JAMA 1991;265(16):2074-8.

2. Hays Lr, Metzler DW. Survey of medical student substance use and parental alcohol use. Sub Abuse 1993;14(1):72-8.

3. Helwick SA. Substance abuse education in medical school: Past, present and future. J Med Ed 1985;60:707-11.

4. Kory WP, Crandall LA. Nonmedical drug use patterns among medical students. Intl J Add 1984;19:871-84.

5. McAuliffe WE, Rohman M, Santangelo S, Feldman B, Magnuson, E, Sobol A, Weissman, J. Psychoactive drug use among practicing physicians and medical students. N Engl J Med 1986;315(13):805-10.
6. Menendez RG, Calabuch ID. El consumo de substancias psicoativas en estudiantes de quinto año de medicina. Rev Hosp Psiquiat Habana 1990;31(2):233-40.

7. Roche AM. Drug and alcohol medical education: evaluation of a national programme. B J Add 1992;87:1041-8.

8. Silva AMA, Souza CB, Marini D, Borges LH, Rahmé ML, Mesquita ME. Prevalência do uso de álcool, cigarro e maconha nos alunos da Faculdade de Medicina da Universidade de São Paulo. Arquivo da Coordenação de Saúde Mental 1985;XLV:134-45.

9. Clark DC, Eckenfels EJ, Daugherty, SR, Fawcett J. Alcoholuse pattern through medical school. JAMA 1987;257:2921-6.

10. Clark DC, Daugherty SR, Baldwin Jr DC, Hughes PH, Storr $\mathrm{CL}$, Hedeker D. Assessment of drug involvement: Applications to a sample of physicians in training. B J Add 1992;87:1649-62. 
11. Fuchs FD. O médico e a questão dos medicamentos: Uma análise crítica sobre os fundamentos da prescrição de fármacos. Ciência e Cultura 1988;40(7):652-5.

12. Maddux JF, Hoppe SK, Costello RM.(1986). Psychoactive substance use among medical students. A J Psych 1986;143(2):187-91.

13. Andrade AG, Bassit AZ, Mesquita AM, Fukushima JT, Gonçalves EL. Prevalência do uso de drogas entre alunos da Faculdade de Medicina da Universidade de São Paulo (19911993). Rev ABP-APAL 1995;17(2):41-6.

14. Andrade AG. Álcool e Drogas: Pesquisa sobre atitudes e uso em estudantes de medicina do Estado de São Paulo. Relatório enviado a FAPESP. 1995.

15. Mesquita AM, Bucaretchi HA, Castel S, Andrade AG. Estudantes da faculdade de medicina da Universidade de São Paulo: Uso de substâncias psicoativas em 1991. Rev ABPAPAL 1995;17(2):47-54.

16. Brenes LFV, Hammes MF, Solé MTV, Hein R, Ramil KAA. Drogas Ilícitas entre Universitários. Rev Assc Méd Rio Grande Sul 1986;30(2):140-43.

17. Carvalho FV. Drug use among university students in the state of São Paulo, Brazil. Bulletin on Narcotics (United Nations Publication) 1986;XXXVIII(1,2):37-40.

18. D’Assumpção EA. Um perfil do uso de drogas entre estudantes universitários. A Folha Médica 1988;97(5):30912.

19. Gorenstein C, Delucia R, Gentil V. Uso de psicoestimulantes e energizantes por universitários. Rev Assc Méd Bras 1983;29(3,4):45-6.

20. Magalhães MP, Barros RS, Silva MTA. Uso de drogas entre universitários: A experiência com maconha como fator delimitante. Rev ABP-APAL 1991;13(3):97-104.

21. Murad JE. Drug abuse among students in the state of Minas Gerais, Brazil. Bulletin on Narcotics 1979;31(1):49-58.

22. Plotnik R, Azmus Ad, Tannhauser M, Tannhauser SL. Utilização de psicotrópicos por estudantes universitários. Rev Pesquisa Médica 1986;20(2):109-13.

23. Zanini AC, Moraes E.C.F, Akerman B, Aizenstein M, Salgado PET. Concept and use of psychoactive drugs among university students in the São Paulo area. Drug Forum 1977;6(2):85-99.

24. Almeida-Filho N, Santana VS, Pinto IM, Carvalho-Neto JA. Is there an epidemic of drug misuse in Brazil? a review of the epidemiologic evidence (1977-1988). Intl J Add 199126(3):355-369.

25. Smart RG, Hughes PH, Johnston LD, Anumonye A, Khant U, Mora MEM, Navaratnam Vposhyachinda V, Varmav K, Wadudk A. A methodology for student drug-use surveys. WHO Offset Publication 50,1980.

26. Schwartz RH, Lewis DC, Hoffman NG, Kyriazi N. Cocaine and marijuana use by medical students before and during medical school. Arch Intern Med 1990;150:883-6.

27. Crofton JW, Fréour PP, Tessier JF. Medical education on tobacco: Implications of a worldwide survey. Med Ed 1994;28:187-96.
28. Bertschy G. Le Programme "Prévention et perfectionnement des médecins dans le domaine de la toxicomanie" (Programme PPMT). Revue Méd Suisse Romande 1993;113:391-392.

29. Fenton GW. Medical education and substance abuse. J Royal Soc Med 1992;85:435-6.

30. Masur J, Zwicker AP. Concepções do estudante de medicina sobre a etiologia do alcoolismo. influências regionais. Ciência e Cultura 1979;31(4):382-8.

31. Paton A. Alcohol misuse and the hospital doctor. B J Hosp Med 1989;42:394-400.

32. Spickard Jr A, Johnson NP, Burger C. Learning through experience: Interviewing real patients?. Alcohol Health Res World 1989;13(1).

33. Brown ME Denton SL, BCSW Vargas IC. A needs assessment of health and wellness services for medical students, residents and faculty. Sub Abuse 1994;15(1):2932.

34. Jorge MR, Masur J. An attempt to improve the identification of alcohol dependent patients in a teaching general hospital. Drug Al Dep 1985;16:67-73.

35. Negrete JC. The role of medical schools in the prevention of alcohol-related problems. Can Med Assc J 1990;143(10):1048-53.

36. Vaillant GE, Sobowale NC, McArthur C. Some psychological vulnerabilities of physicians. N Engl J Med 1972;287:372-5.

37. Martins, LAN. Residência Médica: um estudo prospectivo sobre dificuldades na tarefa assistencial e fontes de estresse. Tese de Doutorado, Escola Paulista de Medicina. 1994.

38. McCue JD. The effects of stress on physicians and their medical practice. N Engl J Med 1982:306:458-63.

39. Burger MC, Spickard WA. Integrating substance abuse education in the medical student curriculum. A J Med Sci 1991;302(1):181-4.

40. Chappel JN, Veach TL, Krug RS. The substance abuse attitude survey: An instrument for measuring attitudes. J Stud Alcohol 1985;46(1):48-52.

41. Coggan PG, Davis AK, Hadac R. Alcoholism curriculum development: An examination of the process. J Fam Prac 1984;19(4):527-32.

42. Goldsmith RJ. Effective education can change attitudes with psychiatric residents. Sub Abuse 1994;15(3):139-45.

43. Mueller TI, Lewis DC. The short story in substance abuse education. Sub Abuse 1994;15(1):47-53.

44. Nocks JJ. Instructing medical students in alcoholism: What to teach with limited time. J Med Ed 1980;55:85864.

45. Adger JR H. Multidisciplinary approaches to medical education in substance Abuse. Sub Abuse 1993;14(1):34.

46. Huguenin M. Du Plaisir a s'occuper de Toxicomanes? Revue Méd Suisse Romande 1993;113:373-8.

47. Korkoc M. How can we teach students about alcoholism? Can Assc J 1984;130:305-8.

48. Aronson SM. Alcoholism and the medical curriculum. Rhode Island Med J 1980;63:11-12. 